Xue-Hong Zhao
Yuan-Qiang Lu

\section{Multiple embolisms resulted from a huge fishbone piercing the left atrium}

Received: 24 January 2014

Accepted: 28 January 2014

Published online: 12 February 2014

(C) The Author(s) 2014. This article is published with open access at Springerlink.com

\section{X.-H. Zhao · Y.-Q. Lu (汭}

Department of Emergency Medicine, First Affiliated Hospital, School of Medicine, Zhejiang University, 79 Qingchun Road, Hangzhou 310003, People's Republic of China e-mail: luyuanqiang201@gmail.com

Tel.: +86-571-87236468

Fax: +86-571-87236469

A 42-year-old woman was admitted with a 2-day abdominal pain associated with fever and a 5-h headache with weakness of the right limbs. Head MRI scan and dispersion showed multiple abnormal signals in the cerebrum and cerebellum hemispheres and abnormal signal lesions in the pons. Computed tomography (CT) showed enlarged spleen with partial infarction. Multiple embolisms were diagnosed, which might have originated from the heart. Cardiac ultrasound showed multiple high level echoes in the left atrium. Chest enhancement CT revealed a spiny body in the anterior wall of the lower esophagus with perforation (Fig. 1) and gastroscopy revealed one wound $30 \mathrm{~cm}$ from the incisors with a fistula formation. The patient recalled having eaten an Asian carp 2 weeks earlier, but did not feel discomfort then. Surgery was performed to remove the foreign body, and left atrial thrombectomy and left atrial repair were performed simultaneously. Perioperatively a fishbone was noted penetrating through the esophageal wall, piercing the left atrium $1.5 \mathrm{~cm}$ deep with a perforation of $0.5 \mathrm{~cm}$ in diameter. Around the fishbone, a large number of excrescences and thrombosis (about $4.0 \times 1.0 \mathrm{~cm}$ ) attached to the left atrial wall. A 4.0-cm-long fishbone was finally removed (Fig. 2). The patient recovered well postoperatively and was discharged 10 days after operation. We have obtained the consent from the patient for

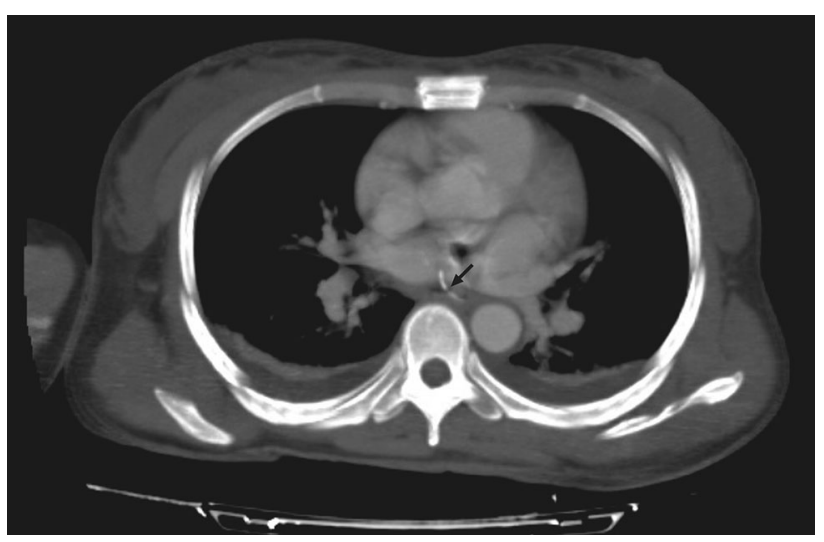

Fig. 1 CT scan showing a spiny body in the anterior wall of the lower esophagus with perforation (arrow)

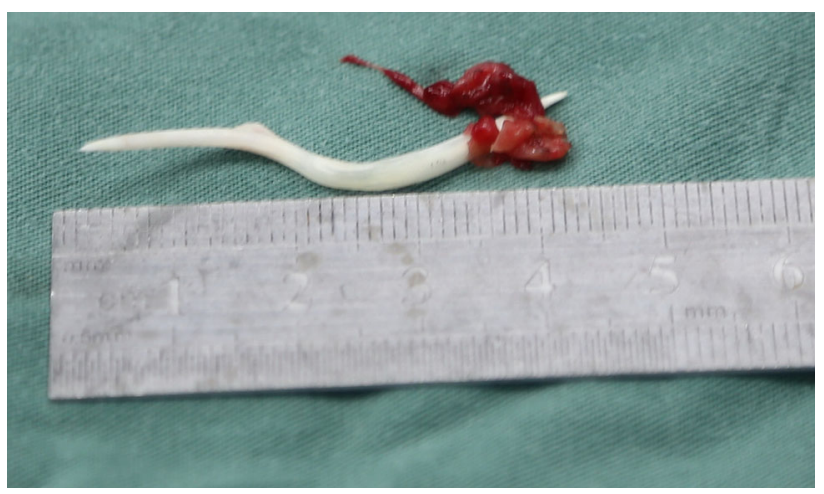

Fig. 2 Gross morphology of a huge fishbone with some excrescences and thrombosis attached 
publication of this case report. Physicians should be alerted to the short- and long-term complications resulting from a fishbone piercing the esophagus and surrounding organs $[1,2]$ and proper treatment should be applied to the patients [3].

Conflicts of interest None.
Open Access This article is distributed under the terms of the Creative Commons Attribution Noncommercial License which permits any noncommercial use, distribution, and reproduction in any medium, provided the original author(s) and the source are credited.

\section{References}

1. Ko SF, Lu HI, Ng SH, Kung CT (2013) Fishbone penetration of the thoracic esophagus with prolonged asymptomatic impaction within the aorta. J Vasc Surg 57:518-520
2. Hung CC, Lee JC, Hsiao LC, Lin YS (2009) Vocal cord immobility caused by the long-standing impaction of a fishbone in the hypopharynx. Laryngoscope 119:228-230
3. Antonelli M, Bonten M, Chastre J, Citerio G, Conti G, Curtis JR, De Backer D, Hedenstierna G, Joannidis M, Macrae D, Mancebo J, Maggiore SM, Mebazaa A, Preiser JC, Rocco P, Timsit JF, Wernerman J, Zhang H (2012) Year in review in Intensive Care Medicine 2011. II. Cardiovascular, infections, pneumonia and sepsis, critical care organization and outcome, education, ultrasonography, metabolism and coagulation. Intensive Care Med 38:345-358 